Research Paper:

\title{
Observing Patients' Rights and the Facilitating and De- Crosshurk terrent Organizational Factors From the Viewpoint of Nurses Working in Intensive Care Units
}

\author{
Syedeh Masoumeh Mousavi ${ }^{1}$, Nooredin Mohammadi ${ }^{\text {*, }}$, Mansoureh Ashghali Farahani ${ }^{2}$ Agha Fatemeh Hosseini $^{3}$
}

1. Department of Critical Care Nursing, Faculty of Nursing and Midwifery, Iran University of Medical Sciences, Tehran, Iran

2. Department of Medical-Surgical Nursing, School of Nursing and Midwifery, Iran University of Medical Sciences, Tehran, Iran

3. Department of Biostatistics, School of Public Health, Iran University of Medical Sciences, Tehran, Iran.

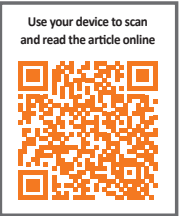

ditat On: Mousavi, S. M., et al., 2017. Observing Patients' Rights and the Facilitating and Deterrent Organizational Factors From the Viewpoint of Nurses Working in Intensive Care Units. Journal of Client-Centered Nursing Care, 3(1), pp. 27-36. https://doi.org/10.32598/jecnc.3.1.27

https://doi.org/10.32598/jcenc.3.1.27

Article info:

Received: 06 Aug. 2016

Accepted: 21 Nov. 2016
Keywords:

Patient's rights, Special care unit, Patient privacy, Facilitating and deterrent organizational factors

\begin{abstract}
A B S T RA C T
Background: The rights of patients admitted to the Intensive Care Units (ICUs) are threatened more than the ones admitted to other hospital wards due to the nature of ICU and special health conditions of the patients admitted such as lower consciousness and their need for invasive and noninvasive care practices. Awareness of obstacles and observance of patients' rights are of particular importance. Therefore, the current study aimed at determining the observance of patients' rights and the organizational facilitators and deterrents influence them from the viewpoint of nurses working in ICUs of educational and therapeutic centers affiliated to Iran University of Medical Sciences, Tehran, Iran.
\end{abstract}

Methods: The current descriptive, cross sectional study included 160 nurses working in ICU, surgery and general wards selected by the census method. Data collection instruments included the 3-section demographic characteristics questionnaire, the Client Observation Checklist (COC) as well as patient safety culture questionnaire. Data were analyzed using SPSS V. 21.

Results: Based on the results of COC, the client observation was $76.16 \%$ in the current study. The highest amount of satisfaction and desirable observance belonged to the information receipt axis (78.34\%) and the lowest observance belonged to the selection and decision making axes (67.17\%). The most important facilitating organizational and deterrent factors to observe the client's rights were identified as reduction of working hours of nurses $(96 \%)$, handling nurses' amenities (94.6\%), inappropriate nurse/patient ratio (92.6\%), and lack of job security and mental safety in nurses $(90.6 \%)$.

Conclusion: Several factors, such as inappropriate nurse/patient ratio, socioeconomic problems, working hours, and heavy workload in a limited time were among the factors influencing the quality of nursing practices, based on the charter of patients' rights.

\section{* Corresponding Author:}

Nooredin Mohammadi, PhD

Address: Department of Critical Care Nursing, Faculty of Nursing and Midwifery, Iran University of Medical Sciences, Tehran, Iran Tel: +98 (919) 2296729

E-mail: nooredin.mohammadi@yahoo.com 


\section{Background}

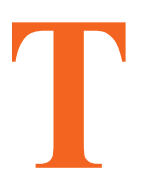

he word "rights" is defined in all cultures and societies as what is right and deserved. Human rights and patients' rights are defined accordingly. Patients' rights are the duties that the medical team has toward the patients such as total privilege, and special abilities or licenses granted to the patient by the law (Buka 2014). Health care providers can play an important role in promoting and protecting human rights to take care of the patients (Reyes et al. 2013).

The idea of the client's rights was raised based on the concept of the person, and dignity and equality of all human beings in the Universal Declaration of Human Rights in 1948 (Babamahmoodi et al. 2011). These rights are derived from medical professional values and ethics (Habib \& Al-Siber 2013) to defend patients' rights and create the required infrastructures to enjoy the sanctity and dignity during the time spending in a health center and ensure non-discrimination to do care of patients with high respect and quality (Kalroozi et al. 2010). For this purpose, the informed consent, confidentiality, privacy, independence, security, respect, choosing treatment, refusing treatment, and participating in the treatment plan are among the patients' right (Habib \& Al-Siber 2013).

In many countries, to achieve patient satisfaction, regulation or charter of patients' rights are announced and implemented by the health care organizations (Mastaneh \& Mouseli 2013). Drafting a Charter of Patient's Rights is among the cases that affect improvement and quality of health of all people in the community and basically it is a method to get information about health and caring affairs they need (Ghodsi \& Hojjatoleslami 2012). Charter of Patient's Rights is the starting point to move in the direction of all-round attention to the provision of patients' rights and the correct definition of the relationship between providers and recipients of health care services (Abedi et al. 2016). Provision of health care services is a complex process that requires careful consideration of human rights (Gonzalo 2013).

Patients' rights are recently introduced in the literature and science of health performance and have become the important part of new health care performance (Almoajel 2012). These rights are fundamental human rights and quality assurance criteria, which protect patients against abused and discriminated and improve moral performances (Kagoya et al. 2013). Another definition of patients' rights is the duties such as observance of legitimate and reasonable physical, psychological, spiritual, and social requirements in most of the standards, and therapeutic rules and regulations, which are the responsibility of health care providers (people working in one of the medical professions including managers and officials of health centers, physicians, nurses, rehabilitation specialists, as well as other therapists) (Gharibi et al. 2014).

In the past, the role of the patients was denied in independence and decision-making power and the doctor and other people of the health team should make a decision for them and the patients should trusted the decisions; therefore, the patient's rights were the same decisions made by the doctor, while in the new definitions of patient's rights, a fundamental change is made in the general perception of the role of the patient, health care affairs, and scope of authorities and patients' decision making (Ingram 1998).

Observing the rights of clients is one of the most important components of providing humanistic and moral care. Many studies are conducted to emphasize the importance of these rights and how to comply with them and also establish many rules and regulations in this field; but to observe these rights in practice, only issuing a statement and directive is not enough and along with that, necessary training to health care providers and also patients and their families are to be considered as an active contributor in the care and treatment affairs (Lukács and Feith 2016). Applying standards of observance of rights protects patients against abuse and racial segregation and promotes ethics (Kagoya et al. 2013).

For the first time in 2002, patients' rights charter was drafted and announced in Iran by the deputy of health, Ministry of Health and Medical Education, and was notified by the Minister of Health and Medical Education to subsidiaries after the revision in November 2011. The comprehensive charter of patients' rights was drafted in 5 general axes and 37 clauses along with insight and value and a final note. Five axes of the charter include the right to receive favorable services, right to receive information sufficiently and desirably, the right to freely choose and decide by the patient in receiving health services, the right to the respect patient's privacy and observance of the principle of privacy, and the right to access an efficient system to deal with complaints each were drafted in paragraphs 14, 4, 7, 9 and 3 clauses, respectively.

One can hope to observe the provisions of this charter when the barriers and facilitators of the implementation of this charter are identified from the perspective of staff, and measures for appropriate culture-building are taken 
according to the views of all beneficiaries including medical treatment staff (Parsapoor, Bagheri \& Larijani 2009).

Factors such as sufficient facilities and expertise, personnel increase, awareness of clients about their rights in the interaction with nurses, allocation of enough time to take care of the client, decreasing the density of patients through increasing the number of hospitals, empowerment of executive and management system, and familiarity with the treatment system are among effective factors in respecting client's rights (Feyzipour et al. 2016). Identifying these factors are of particular importance in a way that identification of facilitating and suppressing factors as a core component of nursing work is the first step to implement the role of patient support; although the ethical guidelines of the nurses acknowledge the responsibility for the support, some nurses feel that they do not have enough power or authority to support the patient and play this role and they are not supported by their employers (Ingram 1998).

Announcing and drafting a charter of patients' rights is an action taken to observe patients' rights. But when it comes to observing its provisions, it is hoped to pay attention to the principles and barriers of implementation of the charter of rights of stakeholder for appropriate culture-building. Eliminating administrative barriers among the organizational factors and staff related factors, which are the major responsibilities of the Ministry of Health and Medical Education, can be the important steps to implement the charter of patients' rights in Iran (Hadianjazi \& Dehghan Nayeri 2015). Nurses are the main health care providers, which constitute $70 \%$ of the health care staff (Komeil-Sani et al. 2015). Based on the charter of the patients' rights, the purpose of the compilation and the necessity of its implementation at the centers is to defend human rights of the patients, particularly, in order to honor and maintain their honor and dignity and make sure that in case of illness, their body and soul are protected against the illness without any discrimination in race, age, gender, rank and social status, education, etc.

It seems that according to the conditions and various facilities of the sections in health centers, to fully observe the rights of patients according to the charter, implementation and enforcement of this charter has its own challenges. Observing patients' rights in the Intensive Care Unit (ICU), as one of the most important parts of the hospital, is of especial importance, due to acute physical conditions and severe injuries to most clients. In ICU, because of the nature of the sector and special conditions of the admitted patients including low consciousness and invasive and non-invasive treatment and care, patients' rights in ICUs are more threatened than other hospital wards and nurses may not pay much attention to these rights. For example, some nurses may refuse to introduce themselves or provide the necessary explanations before caring and providing treatment measures to relatively conscious or half-conscious patients. Also, in ICUs not much attention is paid to patients' privacy as 1 of the 5 pillars of patients' rights.

The patients admitted to ICU cannot control their privacy due to the lower consciousness and their privacy is violated during the medical practices by the treatment team for different reasons. ICU is one of the most important parts of the hospital in which observance of the patients' privacy is of great importance due to inability of the patients to support themselves. Despite the studies in this area, enough information is not still available regarding the attitude of nurses' in ICU toward the patients' rights. Given the increasing importance of patients' rights and in spite of the facilities and technology used in these units, patients' rights are not observed properly.

Given the role of doctors, nurses, and other medical staff in taking care and treatment of patients, in addition to long-term patient-nurse contact during the hospitalization, patients' need to nurses under critical conditions, and the need to respect patients' rights, it seems necessary to conduct a study on nurses' attitude toward the rights of patients admitted to ICU and the strategies to improve the observance of patients' rights. The current study aimed at observing the patients' rights and the facilitating and deterrent organizational factors that affect them from the viewpoint of the nurses working in ICUs of educational and therapeutic centers affiliated to Iran University of Medical Sciences, Tehran, Iran.

\section{Materials \& Methods}

\section{Study design and participants}

The current descriptive, cross sectional study aimed at determining the rights of patients and the facilitating and deterrent organizational factors affecting them from the viewpoint of the nurses working in ICUs.

The research population in the current study included nurses working in internal and surgery wards as well as ICU in the education and teaching hospitals affiliated to Iran University of Medical Sciences holding Bachelor's and higher degrees and at least 6 months of work experience in ICU. The census sampling method was used in the current study. A questionnaire was used as data collection instrument. After obtaining the study protocol approval by the local ethics committee, to attend the hos- 
pitals and collect data, official permissions received from the authorities of Iran University of Medical Sciences.

\section{Data collection}

Researcher attended the hospitals on different days at morning, evening and night shifts. The questionnaires were distributed among the study samples and were collected at the end of the working shift. The study objectives were explained to the subjects, and they were assured about the confidentiality of data and their freedom to withdraw from the study at any time; finally, the informed written consent was obtained from all nurses participating in the study.

Data gathering tool was a questionnaire consisted of 3 parts. The first part was related to demographic characteristics of subjects under study (age, gender, marital status, level of education, work experience, work experience in ICU, employment status, work shift, job rank and working hours per week). The second part of the questionnaire was related to observing the rights of the client and included 4 axes: the right to receive favorable services including respect for patient privacy and the principle of secrecy (11 questions), the right to receive information in an adequate and desirable manner (5 questions), the right to choose and decide freely (4 questions), the right to have access to efficient complaints handling system (4 items) measured based on a 6-option Likert scale from very low to very high options.

The third part was related to organizational factors of the questionnaire concerning observing the client's rights and included 12 items based on a 5-option Likert scale from totally disagree to totally agree options and the results were expressed as percentages. The validity of the Client Observation Checklist (COC) was confirmed in a study by Hadian et al. with Cronbach's alpha coefficient of $89 \%$ and that of the patient safety culture questionnaire related to observing patients' rights in the study by Jouzi et al. (2013) with Cronbach's alpha coefficient of $90 \%$ to $92 \%$. Validity of the questionnaires in the current research was measured by the formal validity method.

\section{Data analysis}

For data analysis, SPSS V. 21 was employed to determine frequency, percentage of frequency, mean and standard deviation.

Table 1. Demographic characteristics of the study subjects

\begin{tabular}{|c|c|c|}
\hline \multicolumn{2}{|c|}{ Demographic Characteristics } & \multirow{2}{*}{$\begin{array}{c}\text { No. (\%) } \\
129(80.6)\end{array}$} \\
\hline \multirow{2}{*}{ Gender } & Female & \\
\hline & Male & $31(19.4)$ \\
\hline \multirow{3}{*}{ Age group, year } & $<30$ & $56(35.0)$ \\
\hline & $30-39$ & $87(54.4)$ \\
\hline & $\geq 40$ & $17(10.6)$ \\
\hline \multirow{2}{*}{ Marital status } & Single & $62(38.75)$ \\
\hline & Married & $98(61.25)$ \\
\hline \multirow{2}{*}{ Level of education } & Bachelor's degree & $151(94.4)$ \\
\hline & Master's degree & $9(5.6)$ \\
\hline \multirow{5}{*}{ Work experience in a particular hospital ward, year } & $<5$ & $69(43.1)$ \\
\hline & $5-10$ & $61(38.1)$ \\
\hline & $10-15$ & $24(15)$ \\
\hline & $15-20$ & $5(3.1)$ \\
\hline & $\geq 20$ & $1(0.6)$ \\
\hline \multirow{3}{*}{ Work hours per week, hour } & $\leq 36$ & $6(3.8)$ \\
\hline & $37-44$ & 75 (46.9) \\
\hline & $\geq 45$ & $79(49.4)$ \\
\hline \multirow{2}{*}{ Awareness of provisions of charter of patients' right } & Yes & $133(83.1)$ \\
\hline & Some what & 27 (16.9) \\
\hline
\end{tabular}

Client-Centered Nursing Care 
Table 2. Nurses' viewpoint about the observance of clients' rights

\begin{tabular}{|c|c|c|c|c|c|c|c|c|}
\hline \multirow[t]{2}{*}{ Level of Confidence } & $\begin{array}{l}\text { Very } \\
\text { Low }\end{array}$ & Low & $\begin{array}{l}\text { Relatively } \\
\text { Low }\end{array}$ & $\begin{array}{l}\text { Relative- } \\
\text { ly High }\end{array}$ & High & $\begin{array}{l}\text { Very } \\
\text { High }\end{array}$ & \multirow{2}{*}{ Mean (SD) } & \multirow{2}{*}{ Percentage } \\
\hline & No. (\%) & No. (\%) & No. (\%) & No. (\%) & No. (\%) & No. (\%) & & \\
\hline Providing healthcare services & & & & & & & & 74.18 \\
\hline $\begin{array}{l}\text { Providing healthcare services deserved } \\
\qquad \text { a client }\end{array}$ & $1(0.6)$ & $2(1.3)$ & $16(10.0)$ & $32(20.0)$ & $59(36.9)$ & $\begin{array}{c}50 \\
(31.3)\end{array}$ & $4.85(1.053)$ & 80.83 \\
\hline $\begin{array}{l}\text { Respecting r cultural and religious values } \\
\text { and beliefs }\end{array}$ & $1(0.6)$ & $6(3.8)$ & $17(10.6)$ & $38(23.8)$ & $58(36.3)$ & $\begin{array}{c}40 \\
(25.0)\end{array}$ & $4.66(1.115)$ & 77.66 \\
\hline Providing timely medical and nursing care & $0(0.0)$ & $1(0.6)$ & $18(11.3)$ & $30(18.8)$ & $61(38.1)$ & $\begin{array}{c}50 \\
(31.3)\end{array}$ & 4.88 (0.999) & 81.33 \\
\hline $\begin{array}{l}\text { Observing the privacy of the client in car- } \\
\text { rying out the medical measures }\end{array}$ & $6(3.8)$ & $8(5.0)$ & $46(28.7)$ & $26(28.7)$ & $39(24.4)$ & $\begin{array}{c}35 \\
(21.9)\end{array}$ & $4.18(0.387)$ & 69.66 \\
\hline $\begin{array}{c}\text { Paying attention to relieve the patients' } \\
\text { pain }\end{array}$ & $2(1.3)$ & $9(5.6)$ & $16(10.0)$ & $28(17.5)$ & $62(38.8)$ & $\begin{array}{c}43 \\
(26.9)\end{array}$ & $4.68(1.206)$ & 78.0 \\
\hline $\begin{array}{l}\text { Transferring a client from a healthcare } \\
\text { center to another upon his/her request or } \\
\text { the family members }\end{array}$ & $5(3.1)$ & $11(6.9)$ & $30(18.8)$ & $28(17.5)$ & $45(28.1)$ & $\begin{array}{c}41 \\
(25.6)\end{array}$ & $4.37(1.386)$ & 72.83 \\
\hline $\begin{array}{l}\text { Inattention to medical care expenses in } \\
\text { emergency situations }\end{array}$ & $3(1.9)$ & $4(2.5)$ & $10(6.3)$ & $25(15.6)$ & $59(36.9)$ & $\begin{array}{c}59 \\
(36.9)\end{array}$ & $4.94(1.142)$ & 82.33 \\
\hline Information & & & & & & & & 78.34 \\
\hline $\begin{array}{l}\text { Providing information to the patient about } \\
\text { the therapeutic method, the possible side } \\
\text { effects and risks }\end{array}$ & 79.16 & $5(3.1)$ & $20(12.5)$ & $32(20.0)$ & $51(31.9)$ & $\begin{array}{c}51 \\
(31.9)\end{array}$ & $4.75(1.160)$ & 79.16 \\
\hline $\begin{array}{l}\text { Introducing supportive systems such } \\
\text { as insurance during the admission and } \\
\text { discharge }\end{array}$ & 79.83 & $6(3.8)$ & $13(8.1)$ & $34(21.3)$ & $62(38.8)$ & $\begin{array}{c}45 \\
(28.1)\end{array}$ & $4.79(1.059)$ & 79.83 \\
\hline $\begin{array}{l}\text { The patients' previous familiarity with the } \\
\text { doctor and nurse }\end{array}$ & 76.5 & $7(4.4)$ & $30(18.8)$ & $29(18.1)$ & $50(31.3)$ & $\begin{array}{c}44 \\
(27.5)\end{array}$ & $4.59(1.200)$ & 76.5 \\
\hline $\begin{array}{l}\text { Giving information about the patient's } \\
\text { disease }\end{array}$ & 79.16 & $4(2.5)$ & $18(11.3)$ & $42(26.3)$ & $\begin{array}{c}55 \\
(34.4)\end{array}$ & $\begin{array}{c}40 \\
(25.0)\end{array}$ & $4.66(1.087)$ & 79.16 \\
\hline $\begin{array}{l}\text { Providing essential training before medical } \\
\text { interventions such as surgery and various } \\
\text { procedures }\end{array}$ & 78.33 & $5(3.1)$ & $15(9.4)$ & $37(23.1)$ & $\begin{array}{c}54 \\
(33.8)\end{array}$ & $\begin{array}{c}46 \\
(28.7)\end{array}$ & $4.70(1.181)$ & 78.33 \\
\hline Decision-making & & & & & & & & 67.17 \\
\hline $\begin{array}{l}\text { Consultation with a doctor except the } \\
\text { selected doctor }\end{array}$ & 78.83 & $5(3.1)$ & $21(13.1)$ & $28(17.5)$ & $\begin{array}{c}55 \\
(34.4)\end{array}$ & $\begin{array}{c}49 \\
(30.6)\end{array}$ & $4.73(1.192)$ & 78.83 \\
\hline $\begin{array}{l}\text { The right to choose and decide on the } \\
\text { therapeutic method and care practice by } \\
\text { the patient or the family }\end{array}$ & 72.66 & $8(5.0)$ & $21(13.1)$ & $41(25.0)$ & $\begin{array}{c}40 \\
(25.0)\end{array}$ & $\begin{array}{c}41 \\
(25.6)\end{array}$ & $4.36(1.412)$ & 72.66 \\
\hline Choosing a doctor by patient or family & 41.83 & $\begin{array}{c}43 \\
(26.9)\end{array}$ & $40(25.0)$ & $14(8.8)$ & $14(8.8)$ & $4(2.5)$ & $2.51(1.351)$ & 41.83 \\
\hline $\begin{array}{l}\text { Ability to leave the hospital with personal } \\
\text { desire and the possibility to participate in } \\
\text { decision-makings }\end{array}$ & 75.5 & $7(4.4)$ & $23(14.4)$ & $36(22.5)$ & $\begin{array}{c}41 \\
(25.6)\end{array}$ & $\begin{array}{c}48 \\
(30.0)\end{array}$ & $4.53(1.336)$ & 75.5 \\
\hline Complaint & & & & & & & & 69.67 \\
\hline The availability of the complaints fund & $1(0.6)$ & $5(3.1)$ & $5(3.1)$ & 35 (21.9) & $46(28.7)$ & $\begin{array}{c}68 \\
(42.5)\end{array}$ & $5.02(1.075)$ & 83.66 \\
\hline $\begin{array}{c}\text { Awareness of the complaints handling } \\
\text { system }\end{array}$ & $5(3.1)$ & $8(5.0)$ & $17(10.6)$ & $32(20.0)$ & $50(31.3)$ & $\begin{array}{c}48 \\
(30.0)\end{array}$ & $4.61(1.317)$ & 76.83 \\
\hline $\begin{array}{l}\text { Indication of the irreparable medical } \\
\text { errors and damages to the patient by the } \\
\text { responsible person }\end{array}$ & $\begin{array}{c}19 \\
(11.9)\end{array}$ & $\begin{array}{c}24 \\
(15.0)\end{array}$ & $43(26.9)$ & $26(16.3)$ & $30(18.8)$ & $\begin{array}{c}18 \\
(11.3)\end{array}$ & $3.49(1.525)$ & 58.16 \\
\hline $\begin{array}{l}\text { Expressing the compensated faults to the } \\
\text { client by the responsible person }\end{array}$ & $\begin{array}{c}17 \\
(10.6)\end{array}$ & $\begin{array}{c}22 \\
(13.8)\end{array}$ & 35 (21.9) & $39(24.4)$ & $28(17.5)$ & $\begin{array}{c}19 \\
(11.9)\end{array}$ & $3.60(1.493)$ & 60.0 \\
\hline
\end{tabular}


Table 3. Nurses' viewpoint on organizational factors related to observance of clients' rights

\begin{tabular}{|c|c|c|c|c|c|c|c|}
\hline \multirow[t]{2}{*}{ Level of Confidence } & $\begin{array}{l}\text { Totally } \\
\text { Disagree }\end{array}$ & Disagree & $\begin{array}{c}\text { No Com- } \\
\text { ment }\end{array}$ & Agree & $\begin{array}{l}\text { Totally } \\
\text { Agree }\end{array}$ & \multirow{2}{*}{ Mean (SD) } & \multirow{2}{*}{ Percentage } \\
\hline & No. (\%) & No. (\%) & No. (\%) & No. (\%) & No. (\%) & & \\
\hline Facilitator & & & & & & & 91.2 \\
\hline Supervising therapeutic procedures & $0(0.0)$ & $2(1.3)$ & $6(3.8)$ & $68(42.5)$ & $84(52.5)$ & $4.46(0.633)$ & 89.2 \\
\hline Availability of sufficient facilities & $0(0.0)$ & $0(0.0)$ & $3(1.9)$ & $60(37.5)$ & $97(60.6)$ & $4.59(0.531)$ & 91.8 \\
\hline $\begin{array}{c}\text { Teaching the rights of the clients to the } \\
\text { nurses }\end{array}$ & $0(0.0)$ & $0(0.0)$ & $11(6.9)$ & $63(39.4)$ & $86(53.8)$ & $4.47(0.624)$ & 89.4 \\
\hline Observance with care standards & $0(0.0)$ & $0(0.0)$ & $4(2.5)$ & $66(41.3)$ & $90(56.3)$ & $4.54(0.548)$ & 90.8 \\
\hline Addressing the amenities of nurses & $0(0.0)$ & $0(0.0)$ & $2(3.1)$ & $39(24.4)$ & $\begin{array}{c}119 \\
(74.4)\end{array}$ & $4.73(0.472)$ & 94.6 \\
\hline Reducing the working hours of nurses & $0(0.0)$ & $1(1.6)$ & $1(1.6)$ & $27(16.9)$ & $\begin{array}{c}131 \\
(81.9)\end{array}$ & $4.80(0.460)$ & 96.0 \\
\hline $\begin{array}{l}\text { Awareness of the clients about their } \\
\text { rights and responsibilities }\end{array}$ & $3(1.9)$ & $5(3.1)$ & $8(5.0)$ & $59(36.9)$ & $85(53.1)$ & $4.36(0.865)$ & 87.2 \\
\hline Inhibitor & & & & & & & 86.8 \\
\hline Nurses' job security and mental safety & $3(1.9)$ & $6(3.8)$ & $4(2.5)$ & $38(23.8)$ & $\begin{array}{c}109 \\
(68.1)\end{array}$ & $4.53(0.868)$ & 90.6 \\
\hline $\begin{array}{l}\text { Failure to support managers and doc- } \\
\text { tors }\end{array}$ & $2(1.3)$ & $21(13.1)$ & $8(5.0)$ & $45(28.1)$ & $84(52.5)$ & $4.18(1.091)$ & 83.6 \\
\hline Inappropriate nurse/patient ratio & $3(1.9)$ & $3(1.9)$ & $1(0.6)$ & $36(22.5)$ & $\begin{array}{c}117 \\
(73.1)\end{array}$ & $4.63(0.766)$ & 92.6 \\
\hline $\begin{array}{l}\text { Nurses' awareness of nurse-patient } \\
\text { communication skills }\end{array}$ & $4(2.5)$ & $6(3.8)$ & $10(6.3)$ & $58(36.3)$ & $82(51.2)$ & $4.30(0.930)$ & 86.0 \\
\hline Failure to observe the rights of nurses & $4(2.5)$ & 27 (16.9) & $5(3.1)$ & $40(25.0)$ & $84(52.5)$ & $4.08(1.208)$ & 81.6 \\
\hline
\end{tabular}

Client-Centered Nursing Care

\section{Results}

Demographic findings of the study participants in the current study are shown in Table 1 . Based on the current study results, the rate of observance was $76.16 \%$. In examining the parameters of the charter of patients' rights in the 4 dimensions under study, the highest score belonged to the information dimension $(78.34 \%)$ and the lowest to the decision-making dimension (67.17\%) (Table 2).

In relation to organizational factors affecting the rights of the clients, the findings of the study showed that the reduced working hours $(96 \%)$ and meeting nurses amenities $(94.6 \%)$ were identified as the most important facilitating factors and on the other hand, the inappropriate patient/nurse ratio (92.6\%), and job and security and mental safety of nurses $(90.6 \%)$ were recognized as the most important deterrent factors on observing the client's rights (Table 3).

\section{Discussion}

Observance of the clients' rights in the current study was $18.86 \%$. Biranwand et al. (2011) expressed observance of the clients' rights in Khorramabad educational hospitals, Iran, 75\%. This rate was different in different studies and hospitals in Iran: $65.2 \%$ in a study in the private centers of the Ray City, $69.1 \%$ in the other study at 22 Bahman Hospital, Gonabad (Basiri Moghadam et al. 2011), 62.4\% in a study in educational hospitals in Mashhad, and $65.2 \%$ in another study in Mazandaran.

The highest score for observance of patients' rights in the current study was obtained in the dimension of information and the lowest score of observance was obtained in the dimension of the decision-making. In the dimension of information, the highest score of observance was related to the introduction of supportive systems such as insurance at admission and discharge, and the lowest 
score of observance was related to familiarity with the doctor and nurse. In the dimension of decision-making, the highest score belonged to the first item; ie, consulting a doctor other than the medical doctor and the lowest obtained score of observance belonged to the third item; ie, choosing doctors by the patients or their families.

In the first dimension of patients' rights charter (providing health care services), the highest mean belonged to the lack of caring the costs in urgent situations and the lowest mean belonged to the ninth item that was the clients' access to medical doctor at any time. In the dimension of the protests, the highest score of clients' rights observance belonged to the first item; ie, the availability of the fund and patient complaints handling system and the lowest score belonged to the third item; ie, the expression of irreparable treatment errors for the client by the responsible person. In the study by Nekoei Moghadam et al. (2014) the highest score of observance of clients' rights belonged to the right to receive favorable health services with $80.5 \%$ and the lowest score belonged to the right to obtain sufficient information at the right time based on the patients' conditions with $39.8 \%$.

Observing the clients' rights in the dimension of receiving optimal health care was $74.17 \%$, which was consistent with $75 \%$ in the study by Amini et al. (2013), and $80.5 \%$ by Nekoei Moghadam et al. (2014). The lowest score of observance was $83.48 \%$ related to the clients' access to their doctor at any time (seventh item). In a study the observance rate for this item was $47.38 \%$ (Khatooni 2010). In connection with the second item of this axis (respect for cultural and religious values and beliefs), observance rate was $77.6 \%$, which was consistent with those of the studies by Jouzi et al. (2013) (78.9\%) and Basiri Moghaddam et al. (2011) (71.70\%).

A study showed that in most cases (60\%) the relationship between the medical staff and the patient was appropriate (Vaskooei Eshkevari et al. 2009). Observance rate for the item of inattention to social class of the client in health care services was $81.83 \%$. This rate was $81.3 \%$ in another study in the item of providing timely medical and nursing care (Khatooni 2010) and it was $85 \%$ in the study by Jouzi et al. (2013), which was consistent with the results of the current study. The score of observance of the confidentiality of the clients' information (item 10) was $69.83 \%$ in the current study and it was $61.1 \%$ in the study by Basiri Moghadam et al. (2011).

The score of observance of item 11 of this dimension (patients' access to the acquaintances during the hospitalization) was $69 \%$ and limited appointment chance in the ICU leads to non-observance of this dimension of the clients' rights. Privacy observance (fourth item of this axis) was $69.66 \%$. In the study by Roudi Rashtabadi et al. (2014) in Kerman, 59.9\% of nurses believed that this right was observed at a good level, Sorkhil et al. (2013) expressed observance of privacy in Cardiac Care Unit $(\mathrm{CCU})$ as $13.13 \%$. In a study in Turkey, patients' privacy was observed in $86.1 \%$ of the cases (Kuzu et al. 2006); Noorian et al. (2016) reported the privacy observance as $62.9 \%$. In another study $31.6 \%$ and $66 \%$ of the patients noticed the privacy observance at good and average levels, respectively (Astaraki et al. 2016).

Observance rate in the dimension of receiving information was desirable and enough as $78.34 \%$. In the study by Amini et al. (2013), this rate was 74\%; however, in the study by Astaraki et al. (2016) it was at moderate and good levels according to the viewpoint of $73.3 \%$ and $16.8 \%$ of the nurses, respectively. Observance of patients' rights in a study on the notification of diagnosis, treatment, and progression of the disease was $69.52 \%$ (Khatooni 2010). In the axis of the right to choose and make informed decisions, the observance rate was $61.17 \%$ in the current study, while in a study it was at good and moderate levels according to the viewpoint of $52.4 \%$ and $42.4 \%$ of the respondents, respectively (Roudi Rashtabadi et al. 2014), and in a study it was $53.33 \%$ from the viewpoint of the patients (Khatooni 2010). In another study $34 \%$ of the patients did not have the right to participate in decision-making and the other half of them did not have the right to refuse the decided therapeutic method or leave the hospital with personal desires (Arab et al. 2010).

The smallest amount of observance of this dimension (choosing the medical practitioner) was $41.43 \%$ and it was $44.7 \%$ in the study by Basiri Moghaddam et al. (2011). In the hospitals of Iran if an emergency patient is admitted, he/she is served by the resident physicians and there is no option to choose a doctor. Even a daily visit by the same doctor is not possible. In a study conducted in Spain, the most common right that the doctors gave to patients was the right to enjoy a proper medical care as a humanistic behavior (Pérez Cárceles et al. 2007). In connection with the axis of the right to access an efficient system of complaints handling, the observance rate was $69.67 \%$. Observance rate was $50.8 \%$ in the study by Nekoei Moghadam et al. (2014). In a study 5.2\% and $83.9 \%$ of the patients evaluated the conditions as good and medium, respectively (Astaraki et al. 2016).

In relation to the facilitator and inhibitor organizational factors of observing the clients' rights, the 2 phrases of 
"reducing work hours for nurses facilitates the observance of clients' rights" with an average of 4.80 (96\%) and "nurses' amenities facilitates the observance of clients' rights" with an average of $4.73(94.6 \%)$ were the phrases that nurses considered as the most important facilitating factor and the 2 phrases of "the inappropriate nurse/patient ratio" (92.6\%) and "nurses' occupational and psychological safety" (90.6\%) were introduced as the most important deterrent factors by the nurses. In the study by Jouzi et al. (2013) two phrases of "reducing nurses' work hours (90\%)" and "the nurse/patient ratio (91.7\%)" were considered as the most important organizational factors.

Based on a study conducted on clients' rights, eliminating organizational barriers attributed to consumer rights had a significant impact on promoting the rights of the client. Usually, nurses are in closer contact and in a better position to support patients, but until now, they did not have such a role due to shortages of personnel, lack of time, and lack of appropriate training in this regard (Merakou et al. 2001). Almost within all realms of healthcare, nurses have the main role, at the bedside of their patients, providing medical treatments and preventing subsequent errors, reducing infection rate, facilitating patient safety, and taking care of them to pass the acute phase of the disease and return to the recovery stage and be discharged from the hospital (Morgan \& Somera 2014).

Among the most important and main obstacles of failure to observe patients' rights were socioeconomic problems and heavy workload of care providers, especially nurses. Specific workplace constraints including working hours and excessive contact with patients and companions, heavy workload in a limited time, large number of patients, fatigue and lack of manpower, multiple shifts, and working overtime were among the factors affecting nurses' performance in implementing the charter of patient's rights. Failure to observe the rights of nurses can also lead to a lack of observance of patients' rights. Fatigue, unsatisfactory economic conditions along with multiple work shifts, job dissatisfaction, unsuitable work environment, lack of facilities, lack of personnel along with a large number of clients, as well as heavy workload and lack of job security indicate the negligence in nurses' rights, which result in non-observance of patients' rights.

Findings of the current study indicated that in spite of respecting the clients' rights at the desired level, in reviewing questions one by one, some cases were not observed. Providing training programs for the health care providers in the field of clients' rights, approval of laws and regulations to guarantee the rights of the clients, implementation of the instructions to monitor these rights, tracking clients' rights violations were among the items, which should be considered more by the officials and policy makers. To resolve the problems of the observance of rights comprehensive national rules and regulations are required; in addition, it is not possible only through changing the attitudes and behavior of doctors and nurses.

In the context of observing patients' rights in the health centers, only issuing a statement and the directive is not enough and the 2 basic principles of training and implementing the charter of patients' rights should also be considered. Health care providers should be aware of patients' rights and the possible consequences of ignoring them. The results of the current study are expected to draw attention of the authorities to the need for continuous education of doctors and nurses. By estimating the shortage of nursing staff and attracting the right people, senior system managers can provide the necessary ground to improve the quality of caring affairs. The results of the studies in the fields of nursing and medical management and education can be cited and used.

It is suggested to observe patients' rights in a descriptively observational format by doctors and nurses; in addition, the reasons for neglecting these rights and inattention of healthcare managers should be investigated to take effective measures and ensure about the observance of the patients' and the increase of their satisfaction.

\section{Acknowledgments}

This article is part of a MSc. thesis which was financially supported by Iran University of Medical Sciences. It was approved by the Ethics Committee of School of Nursing and Midwifery of Iran University of Medical Sciences, No. IR.IUMS.REC.1394.9211449204, dated $26 / 01 / 2016$. Authors hereby wish to thank the professors and nurses working in educational and therapeutic hospitals affiliated to Iran University of Medical Sciences and all those who contributed to the research.

\section{Conflict of Interest}

The authors declared no conflicts of interest. 


\section{References}

Abedi, G., et al., 2017. Awareness and observance of patient rights from the perspective of Iranian patients: A systematic review and meta-analysis. Iranian Journal of Medical Sciences, 42(3), pp. 227-34. PMCID: PMC5429490

Almoajel, A. M., 2012. Hospitalized patients' awareness of their rights in Saudi governmental hospital. Middle-East Journal of Scientific Research, 11(3), pp. 329-35.

Amini, A., Tabrizi, J. S. \& Shaghaghi, A., 2013. The status of observing patient rights charter in outpatient clinics of Tabriz University of Medical Sciences: Perspectives of health service clients. Iranian Journal of Medical Education, 13(7), pp. 611-22.

Arab, M., Zarei, A. \& Hosseini, M., 2010. Awareness and observation of patients' rights from the perspective of patients: A study in university hospitals in Tehran. Journal of School of Public Health and Institute of Public Health Research, 8(2), pp. 77-86.

Astaraki, P. , et al., 2016. Obsevance patients bills of rights from patients perspective in hospital of Khoramabad. Yafte, 17(1), pp. 5-14.

Babamahmoodi, F., et al., 2011. Observation of patient's right charter in Mazandaran teaching hospitals: Patients view. Iranian Journal of Medical Ethics and History of Medicine, 4(4), pp. $37-44$.

Basiri Moghadam, K., et al., 2011. Health providers and patients awarness on patient bill of rights and its observing rate in 22 Bahman Hospital. The Horizon of Medical Sciences, 17(1), pp. 45-54.

Buka, P., 2014. Patients' rights, law and ethics for nurses. Florida: CRC Press. doi: 10.1201/b13463

Feyzipour, H., et al., 2016. Evaluation of the patients rights fasilitator factors, with an emphasize on the charter of patients'rights (A case study of nurses' attitudes in public hospitals of Urmia). Journal of Urmia Nursing and Midwifery Faculty, 14(8), pp. 692-701.

Gharibi, F., et al., 2014. Effective interventions on service quality improvement in a physiotherapy clinic. Health Promotion Perspectives, 4(1), pp. 61-7. doi: 10.5681/hpp. 2014.008

Ghodsi, Z. \& Hoijatoleslami, S., 2012. Knowledge of students about patient rights and its relationship with some factors in Iran. Social and Behavioral Sciences, 31, pp. 345-8. doi: 10.1016/j. sbspro.2011.12.065

Gonzalo, G., 2013. Human rights and informed consent in clinical practice: Beyond the right to health. Revista Peruana de Medicina Experimental y Salud Pública, 30(2), pp. 315-9.

Habib, F. \& Al-Siber, H., 2013. Assessment of awareness and source of information of patients' rights: A cross-sectional survey in Riyadh Saudi Arabia. American Journal of Research Communication, 1(2), pp. 1-9.

Hadian Jazi, Z. \& Dehghan Nayeri, N., 2015. Barriers in the performance of patient's rights in Iran and appropriate offered solutions review article. Journal of Holistic Nursing And Midwifery, 24(4), pp. 69-79.

Ingram, R., 1998. The nurse as the patient advocate (monograph on the internet). Portsmouth: University of Portsmouth Pub.
Jouzi, H., et al., 2013. Investigate organizational factors associated with patient rights from viewpoint nurses and patients in educational hospitals affiliated to the Ilam University of Medical Sciences. Journal of Medical Ethics, 7(23), 141-60.

Kagoya, H. R. et al., 2013. Awareness of, responsiveness to and practice of patients' rights at Uganda's national referral hospital. African Journal of Primary Health Care $\mathcal{E}$ Family Medicine, 5(1). doi: 10.4102/phcfm.v5i1.491.

Kalroozi, F., Dadgari, F. \& Zareiyan, A., 2010. Patients' satisfac tion from health care group in patient's bill of right observance. Journal of Military Medicine, 12(3), pp. 143-8

Khatooni, S., 2010. The rate of preserving patients' rights chart in state hospitals in Qazvin, Iran. Journal of Medical Rights, 3(11) pp. $171-88$

Komeili-Sani, M., et al., 2015. The relationship between nurses' clinical competency and job stress in Ahvaz university hospital, 2013. Journal of Clinical Nursing and Midwifery, 4(1), pp. $39-49$

Kuzu, N., Ergin, A. \& Zencir, M., 2006. Patients' awareness of their rights in a developing country. Public Health, 120(4), pp. 290-6. doi: 10.1016/j.puhe.2005.10.014

Lukács, Á. \& Feith, H. J., 2016. Betegjogok etnikai metszetben. Orvosi Hetilap, 157(18), pp. 712-7. doi: 10.1556/650.2016.30424

Mastaneh, Z. \& Mouseli, L., 2013. Patients' awareness of their rights: Insight from a developing country. International Journal of Health Policy and Management, 1(2), pp. 143-6. doi: 10.15171/ ijhpm.2013.26

Merakou, K., et al., 2001. Satisfying patients' rights: A hospital patient survey. Nursing Ethics, 8(6), pp. 499-509. doi: $10.1177 / 096973300100800604$

Moghaddam, M. N., et al., 2016. Awareness of patients' rights charter and respecting it from the perspective of patients and nurses: A study of limited surgical centers in Kerman city, 2013. Bioethics Journal, 4(11), pp. 31-56. doi: 10.22037/ bj.v4i11.14179

Morgan, D. \& Somera, P., 2014. The future shortage of doctoral prepared nurses and the impact on the nursing shortage Nursing Administration Quarterly, 38(1), pp. 22-6. doi: 10.1097/ naq.0000000000000001

Nekoei Moghaddam, M., et al., 2014. Awareness of Patients rights charter and respecting it from the perspective of patients and nurses: A study of limited surgical centers in Kerman city, Bioethics Journal, 4(11), pp. 31-56.

Noorian, K., et al., 2016. Comparison of operation room staffs and patients perspectives from "patient privacy" in the operating room. Journal of Clinical Nursing and Midwifery, 5(1), pp. 47-57.

Parsapoor, A., Bagheri, A. \& Larijani, B., 2009. Patient rights in Iran. Journal of Medical Ethics and History of Medicine, 3, pp. 39-47.

Pérez Cárceles, M.D. et al., 2007. Actitudes de los médicos de familia hacia los derechos de los pacientes. Atención Primaria 39(1), pp. 23-8. doi: 10.1157/13098275.

Reyes, H., et al., 2013. Incorporating human rights into reproductive health care provider education programs in Nicaragua and El Salvador. Revista Panamericana de Salud Pública, 34(1), pp. 54-9. 
Roudi Rashtabadi, O., Borhani, F. \& Abbaszadeh, A., 2014. Awareness of patients' rights and observance and effective factors from nurses perspective in Kerman. History of Medicine Journal, 5(17), pp. 37-62.

Sarkhil, H., Darvishpoor-Kakhaki, A. \& Borzabadi-Farahani, Z., 2013. Respecting patient's privacy in cardiac care units of Tehran selected hospitals. Iranian Journal of Cardiovascular Nursing, 2(2), pp. 40-7.

Vaskooei Eshkevari, K., Karimi, M., Asnaashari, H. \& Kohan, N., 2009. [The assessment of observing patients' right in Tehran University of Medical Sciences' hospitals (Persian)]. Medical Ethics and History of Medicine, 2(4), pp. 47-54. 